\title{
Students' Impressions of Online Learning in Albania
}

\author{
Najada Quka \\ PhD, Sports University of Tirane \\ Faculty of Social Sciences and Education
}

\section{Abstract}

The consequences of epidemic Covid-19 forced the education sector around the world to face online learning among these two last years. Many countries in the world had to face this new and very difficult challenge. Unfortunately, the education system of Albania was one of those that had to overcome the difficulties and continue the academic year for all its levels. The main purpose of our study was to analyze the impression of Sports University of Tirana's students about some aspects of online learning. In this study, we used a closed questionnaire, distributed through the Microsoft Teams application and the descriptive analysis to interpret the collected data.Participants in this study belong to the"Sports University of Tirana", Professional Master in PreUniversity Education Teacher. Results were collected by 218 students ( $\mathrm{N}=$ 218 ) of which $61 \%$ of them were male and $39 \%$ female. According to the age of the student, there was a frequency of $29 \%$ of $21-22$ years old, $50 \%$ of 23 24 years old, and $21 \%$ of over 25 years old. The results showed that only $18 \%$ of participants disagreed with online learning reinforcing the absence of practices. Unfortunately, these absences rose in them insecurity to fulfill their future mission as Physical Education Teacher. In conclusion, student's impressions about online learning showed the irreplaceable importance of practical classes for them. Despite the aggravated situation created by Covid19 , online learning for all universities with specific curricula due to practical classes should be combined with auditor classes to improve academic performance.

Keywords: online teaching, face-to-face class, academic performance, student's online impression

\section{Introduction}

The evolutionary daily life of human beings unfortunately in 2019 was threatened by radical changes in various sectors around the world including Albania. A year that marked the beginning of this treacherous pandemic called Covid 19 (UNESCO, 2020). To prevent the prevalence of Covid 19 the Albanian government was forced to take extreme measures affecting the normality of education facing all its levels with the 
online version, a new and very difficult experience. The decision to replace classroom teaching with online learning perhaps was not desirable but appropriate for the aggravated situation.Implementing online learning at the national level was completely new and not easy for Albania, unlike developed countries where online learning was already a familiar experience.

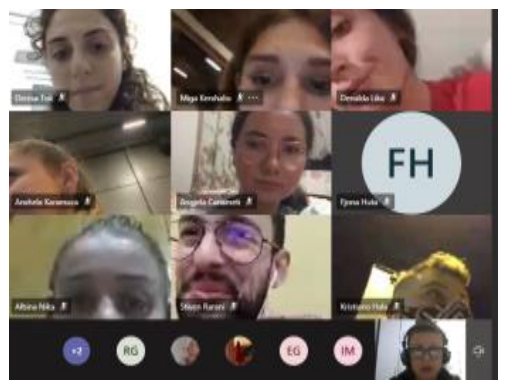

The implementation of online learning was violated by some important criteria such as digital knowledge, technical and communication aspects. Internet network, which turned out to be unstable, is the most demand acquisition to make the online platform work. Its absence affects the teaching, learning process affecting the evaluation as one of the most important parts for both of them (Adedoyin \& Soykan, 2020). Digital competencies that resulted influenced by socio-economical aspects reducing so the flexibility to access the online platform and to be part of online classes (Alsoud \& Harasis, 2021). These criteria were underlined as barriers in other studies that pointed them out as the biggest challenge in the online learning process (Adedoyin \& Soykan, 2020; Heng \& Sol, 2020). Furthermore they resulted to become the cause for the disagreement of $43 \%$ of English language students of Taibah University in Saudi Arabia to continue with online learning (Mahyoob, 2020). These impressions are results of social interaction and face-to-face contact absence that makes the learning and perception process difficult in many ways (Williams, 2013). The period of the Covid 19 pandemic in Indonesia was described as one of the biggest teaching challenges to ensure the continuity of academic activity. Regarding the appropriate learning method for their Physical Education students in this situation, foreign studies focused more on discovering the appropriate forms of teaching due to the needs and interests of student'saccomplishments (Jumareng, 2021). The variety of online learning impressions are the result of many factors where for some students online learning at the study of Apriyanto and his colleague was perceived as effective ( $8.3 \%$-very effective; $36.9 \%$ effective) while for others as ineffective $(11.6 \%$ ineffective and 2.9 very ineffective). Nevertheless, they expressed that online learning is the best solution to the situation; it was not the mostproductive form of learning especially in physical education (Apriyanto \& Adi, 2021). Despite every difficulty of online learning but influenced by the aggravated situation of the pandemic, $44.2 \%$ of Indonesia Dental University students preferred online learning compare to auditorium class (Amir et al., 2020). Hence the students of Deakin University in 2005 expressed their satisfaction with online learning emphasizing the flexibility that it 
provides and the ability to study everywhere they are (Goldwell, Craig, \& Gold, 2006). Also the current studies highlight the positive value of online learning particularly for the created health situation, underlining the most frequent problems facing during its implementation for both teachers and learners (Williams, 2013; UNESCO, 2020). Therefore, our study aimed to investigate quantitatively the impression of students about online learning focusing on overcoming the detected barriers. The perceptions of the key users, students in our case, are important measures especially their satisfaction with the online learning classes.

\section{Methodology}

This study was a descriptive analysis of a closed questionnaire data collected from 218 students $(\mathrm{N}=218)$ of the Sports University of Tirana, Albania. The participants were undergraduate students' of Professional Master's study cycle, who as Physical Education future Teachers realized their studies almost online. To evaluate their impression about online learning we used a closed questionnaire designed by a group of students who were not involved in the study. Initially it was piloted with 20 of them, and then distributed to all students of the Professional Master cycle $(\mathrm{N}=300)$. Only $73 \%$ could submit the completed questionnaire through the same platform "Microsoft TEAMS" we used for the online learning process. For the literature review, we focused our investigation more on those articles that online learning among students was the keyword for them, fund in PubMed and Research Gate.

\section{Results}

In this study participated 218 students of Physical Education with the exact age, gender and course frequency such as $38 \%$ were from course I, $62 \%$ from Course II, $39 \%$ female, $61 \%$ male, $29 \%$ of them were $21-22$ years old, $50 \%$ were $23-24$ years old and $21 \%$ the participants were over 25 years old. These results showed dominated participants of males, aged 23-24 years old from the second course of Professional Master. Only 27\% of students couldn't complete the questionnaire because of the technical difficulties to receive it via Microsoft Teams. (Graphic.1, 2, 3).

Graphic 1:

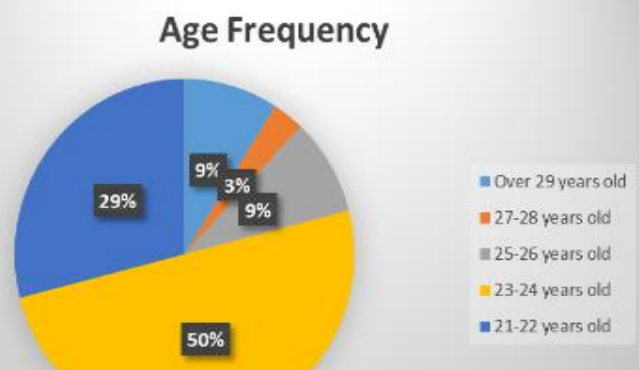


Graphic 2:

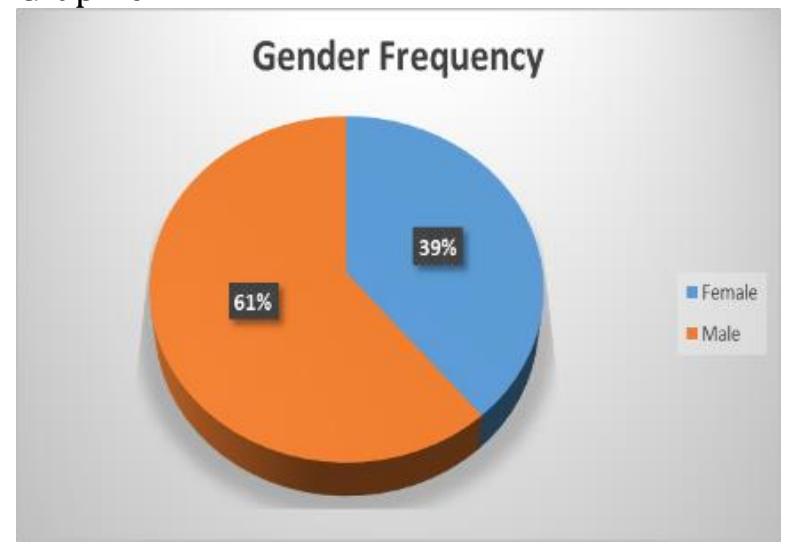

Graphic 3:

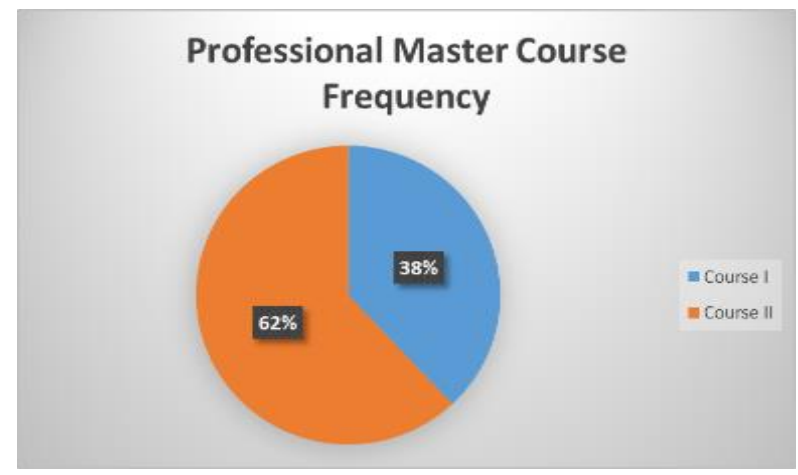

The first question comes out because of two reasons, from a semi-semester online learning experience and from the online learning decision taken by the Albanian government a few days before university started. The consequences of this quick decision were reflected in the results where $51 \%$ of students expressed partial agreement, $31 \%$ full agreement and only $18 \%$ of them did not agree at all to continue their education online. (Graphic.4) Because of several factors such as "lack of internet" (49\%), lack of technological knowledge (19\%), and the socio-economic level (60\%), that prevent $15 \%$ of the student to have and apply the correct electronic equipment during online learning, affected their participation, getting information, delivering their assignments. (Graphic.6) Only 54\% of participants showed no difficulties accessing online classes. (Graphic.5) Regarding the Impressions of our students about online learning, influenced by the above-mentioned barriers, resulted that $16 \%$ of students perceived it $100 \%$ effective, $30 \%$ of students perceived it $75 \%$ effective, while $16 \%$ of them perceived it $25 \%$ effective. (Graphic. 7 ) 
Graphic.4: Did you agree with the decision of the government to continue online learning?

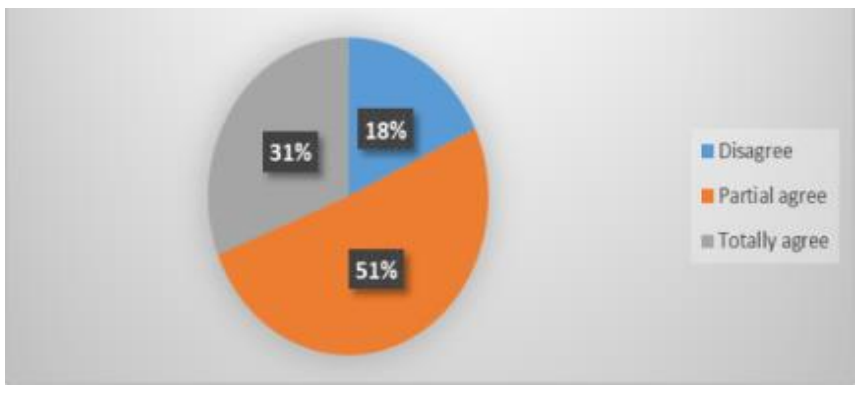

Graphic.5: Have you encountered difficulty accessing the online platform?

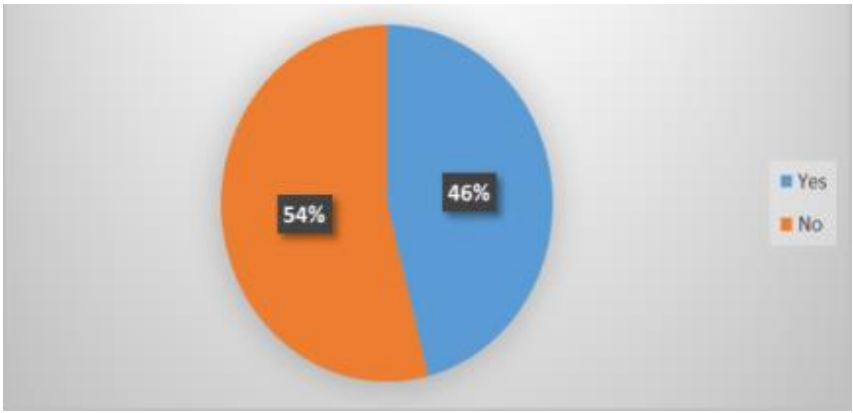

Graphic.6: Problems during online learning were because of? Graphic.7: How much effective online learning has been?
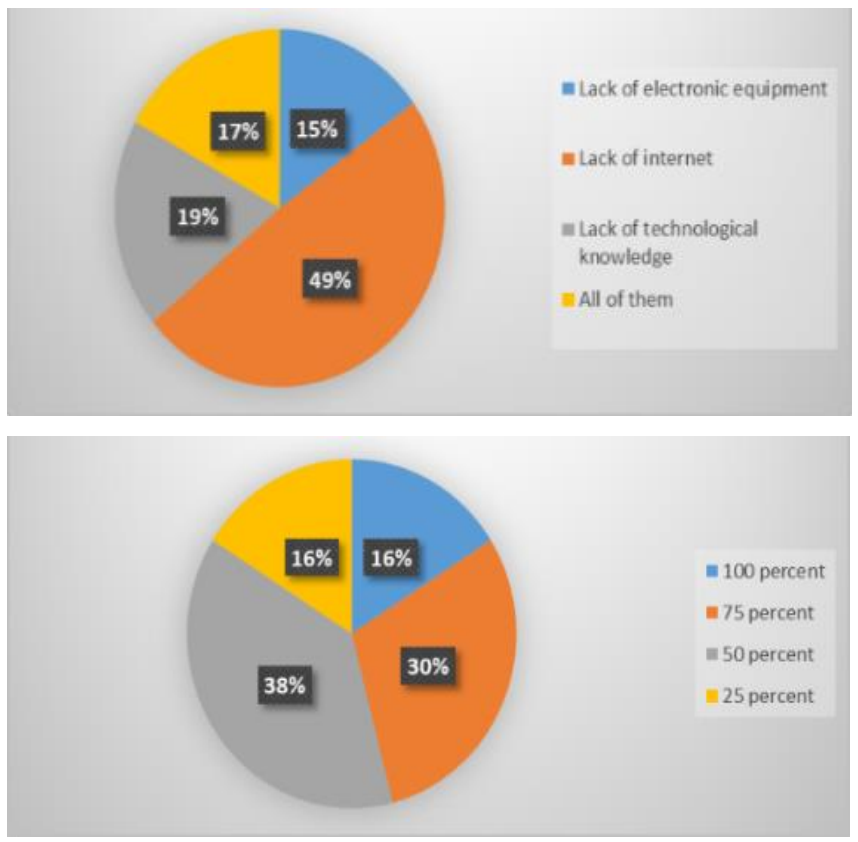
Despite all difficulties that our students faced during online learning showed their supportive impression for online classes by $25 \%$ of them, while the rest (75\%) underlined the irreplaceable importance ofauditor practices. (Graphic.8) Results have shown also that Microsoft Teams has been the easiest online platform touse (49\%) and the most productive (59\%) compare to Google classroom and Zoom Meet. (Graphic.9)

Graphic.8: Do you miss auditorium?

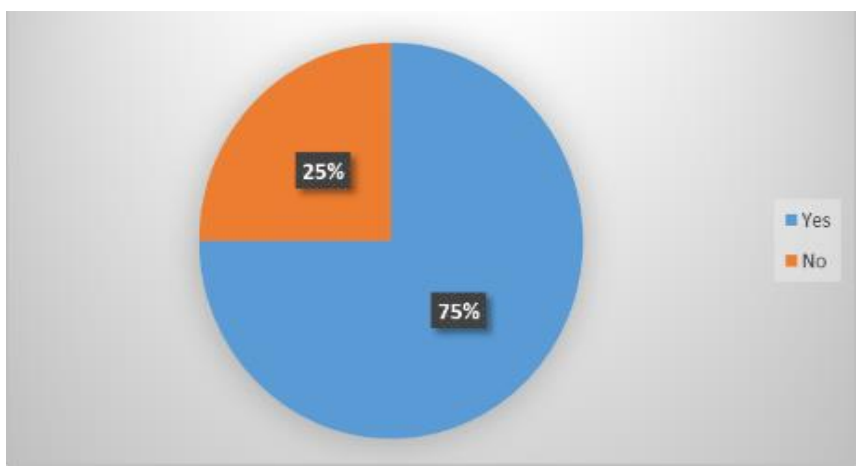

Graphic.9: Most productive and easiest online platform.

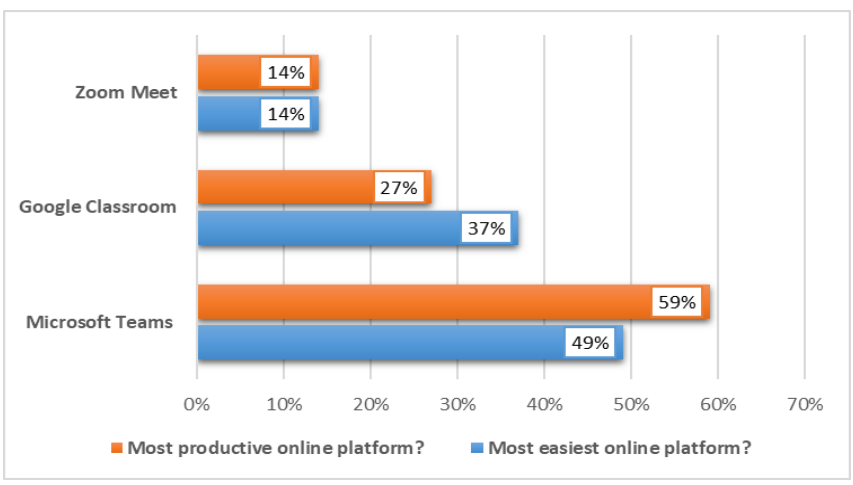

Our results showed a variety of impressions about online learning because of many factors underlining that this new experience found us unprepared in many aspects affecting the teaching and learning process. The negative impressions about online learning are results of the specificity of our university where practical classes dominate and play an important role in the curriculum of our study programs.

\section{Discussion}

Online learning became an inevitable challenge for the education system all around the world, even more for Universities with practical specifics like Tirana Sports University (UST), where online learning did not favor practice at all. Other studies emphasized the important role of practical classes and the big gap that only auditorium class can improve it (Heng \& Sol, 2020). 
The sudden decision was taken by the Albanian Government very close to the beginning of the academic year 2020-2021 and because of many other barriers, it was not well received by our students influencing their impression regarding the agreement to start their studies online. This expression class was supported also by other authors who had done similar studies respectively in Indonesia, Cambodia, and Saudi Arabia Universities (Heng \& Sol, 2020; Adedoyin \& Soykan, 2020; Mahyoob, 2020).

Our study identified the lack of internet (49\%) as one of the most barriers that influenced the online learning process, supported by other authors who have respectively reported this absence of internet respectively by $48.6 \%$ and $48 \%$ of their participants (Adedoyin \& Soykan, 2020; Apriyanto \& Adi, 2021).

About the impressions of online learning efficacy, our results showed $75-100 \%$ effectiveness by $46 \%$ of the students and $25-50 \%$ effectiveness by $54 \%$ of them. These frequencies of online learning efficacy were detected even by Apriyanto and his colleague who reported the same tendency (Apriyanto \& Adi, 2021).

Despite these impressions, students reported that online learning was the only adequate method during this unstable situation created by Covid-19 underlining also the necessity to be improved in the future. According to our study, the absence of an auditorium, because of many issues that online classes do not enable the learning process can not offer, was perceived by $75 \%$ of our students adding the necessity of practical classes in their education. Following the same line, Amir and his colleagues supported our results detecting that $44.2 \%$ of Indonesia Dental University students preferred more online learning compare to auditorium class (Amir et al., 2020).

It is well shown from our results and other authors that online learning was the best solution to prevent the prevalence of Covid-19 and to continue the education process for all. In our study, we discovered that Microsoft Temas was the easiest (49\%) and productive (59\%) online platform compare to Google Classroom and Zoom Meet. Another study showed the same tendency about the Microsoft Teams (49\%) as the most used application during online learning (Alsoud \& Harasis, 2021).

We can't say the same for other authors who noted "WhatsApp" as the most used online platform respectively $72.2 \%$ and 43.2\% (Mahyoob, 2020; Apriyanto \& Adi, 2021). Online learning has been the only method that the education system all around the world was forced to apply. For many of us, this unexpected situation was a challenge that had to do with some barriers that exceeded our professional competencies to adapt in terms of improving teaching.

\section{Conclusion}

Inthis investigation impression of our Physical Education students about online learning showed that online learning can be effective particularly for theoretical subjects. We cannot say the same for the practice class where the auditorium is irreplaceable. Online learning was negatively affected by some barriers that in the 
future the educational policy must pay attention providing workshops improving the technical knowledge of teachers and students, including the necessary of the internet network facilitating the online access, and considering the combination between online and auditorium classes for a more effective learning process. In the end, we underline the need for future studies to gather as many impressions about online learning as we can to improve all advantages of online learning detected via other studies.

As conlusion we emphasize that the direction of the following studies shoud be the improvement of online teaching methds by increasing its efficiency and its benefits due to better academic performance of students. To achieve this improvement our study demonstrates that the focus should be on increasing the attention of students during online lessons and to create more attractive online classes. Also it is very important to think about the way how to skip the difficulties that students got from the practical classes' absence. It is imediatory to think about new ideas how to create adoptive online practical classes, even the benefits can not be the same as the auditorium. In order to minimize the advanteges of online learning and to maximize the benefits of it, we should go through more detailed and specific studies.

\section{Recommendations}

These data can provide the basis for planning preventive strategies to enhance the efficacy of online learning. Many impressions showed us that online learning can be as effective as auditorium class can for the theoretical subjects but teaching methods needs some adaptation due to motivation and organizing active lectures including students into a group discussion. Improvement of online teaching method should be focused on us much as interesting ways to draw the students' attention that unfortunately, as a result of not being confronted, it decreases more and more by making the communication further difficult. Online learning has been the most important and difficult mission of the Albanian education system since March 2019. We tried to get the best from this new experience but impressions told us that many improvements are necessary to be done due to online learning starting from better communication and being a better listener related to students who had to face this difficulty at the most important time of their life such as their education. For a better learning performance online method need improvements due to an easy learning process by increasing the benefits of online learning stimulating a better relationship between students and lecturer. Both of educative actors, students and lecturer, needs new instructions and help to easily implement this new learning method in order to benefit both of them from this process, as much as it provides.

\section{References}

[1] Adedoyin, O. B., \& Soykan, E. (2020). Covid-19 pandemic and online learning: the challenges and opportunities. Interactive Learning Environments, 1-13. https://doi.org/10.1080/10494820.2020.1813180. 
[2] Apriyanto, R., \& Adi, S. (2021). Effectiveness of online learning and physical activities study in Physical education during Pandemic Covid 19. Kinestetik: Journal IlmiahpendidikanJasmani 5 (1); pg.64-70. ISSN 2685-6514 (online).

[3] Alsoud, A. R., \& Harasis, A. A. (2021). The impact of COVID-19 Pandemic on Student's E-learning Experience in Jordan. J.Theor.Appl.Electron.Commer.Res. 16, 1404-1414. https://doi.org/10.3390/jtaer16050079.

[4] Amir, L. R., Tanti, I., Maharani, D. A., Wimardhani, Y. S., Julia, V., Sulijaya, B., \& Puspitawati, R. (2020). Student perspective of classroom and distance learning during Covid-19 pandemic in the undergraduate dental study program Univeristas Indonesia. BMC, Medical Education, 20:392. https://doi.org/10.1186/s12909-020-02312-0.

[5] Heng, K., \& Sol, K. (2020).Online learning during Covid 19: Key challenges and suggestion to enhance effectiveness. Short article series, Cambodian Education Forum (CEF); pg: 1-15.

[6] Jumareng, H., Setiawan, E., Patah, I. A., Aryani, M., \& Gani, R. A. (2021). Online Learning and Platforms Favored in Physical Education Class during Covid 19 Era: Exploring student perception. International Journal of Human Movement and Sports Sciences 9 (1):11-18. http://www.hrpub.org.

[7] Mahyoob, M. (2020). Challenges of e-Learning during the COVID-19 Pandemic Experienced by EFL Learners. Arab World English Journal, 11 (4) 351-362. DOI: https://dx.doi.org/10.24093/awej/vol11no4.23.

[8] Williams, L. M. (2013). A case study of virtual physical education teachers' experiences in and perspectives of online teaching. Graduate theses and Dissertations. The University of South Florida. http://scholarcommons.usf.edu/etd/4962.

[9] UNESCO. (2020). COVID-19 Webinar: A new world for teachers, education's frontline workers. Taken by https://en.unesco.org/news/covid-19webinar-new-world-teachers-educations-frontline-workers.2020

[10] Goldwell, J., Craig, A., \& Goold, A. (2006). Student perspectives of onine learning. Conference paper, part 2, paper 711, ALT-C; Research Proceedings, pg. 97-107.https://www.researchgate.net/publication/233725899 